\title{
Impact of COVID-19 Pandemic on Sexual Minority Populations in Brazil: An Analysis of Social/Racial Disparities in Maintaining Social Distancing and a Description of Sexual Behavior
}

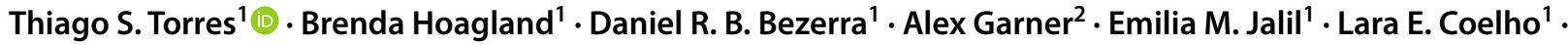 \\ Marcos Benedetti ${ }^{1} \cdot$ Cristina Pimenta $^{3} \cdot$ Beatriz Grinsztejn $^{1} \cdot$ Valdilea G. Veloso ${ }^{1}$
}

Published online: 31 July 2020

๑) Springer Science+Business Media, LLC, part of Springer Nature 2020

\begin{abstract}
We conducted a web-based survey to understand the impact of social distancing measures on Brazilian MSM and transgender/non-binary lives. A total of 3486 respondents were included in this analysis and the great majority were cismen (98\%). The median age was 32 years (IQR: 27-40), 44\% non-white, 36\% low schooling and 38\% low income. Most of participants reported HIV negative/unknown status (77\%). Participants on-PrEP reported more condomless anal sex than those off-PrEP. Conversely, 24\% off-PrEP were at substantial HIV-risk. PrEP/ART continuation were reported by the majority, despite reports of impediments to medication refill. Transgender/non-binary reported more mental health problems and challenges to access health care. Social and racial disparities were associated with unattainability of maintaining social distancing. Tailored social and economic support policies during COVID-19 pandemic should be made available to these populations. Challenges for PrEP/ART access will demand the implementation of innovative solutions to avoid the expansion of the HIV epidemic.
\end{abstract}

Keywords MSM $\cdot$ Transgender people $\cdot \operatorname{PrEP} \cdot$ Covid-19 $\cdot$ Brazil

\section{Introduction}

On March 11, 2020 the World Health Organization (WHO) recognized the novel coronavirus (SARS-CoV-2) disease 2019, or "COVID-19", as a pandemic months after the initial reports from Wuhan, China in December, 2019 [1]. Brazil at the present has the second-highest number of confirmed SARS-CoV-2 cases in the world. From February 26, 2020 to July 30, 2020 there have been more than 2,500,000 confirmed cases and more than 90,000 deaths in the country [2]. The Southeast region account for the largest number of cases, although incidence and mortality rate per 100,000/ inhabitants is higher in the North region [2].

Thiago S. Torres

thiago.torres@ini.fiocruz.br

1 Fundação Oswaldo Cruz, Instituto Nacional de Infectologia Evandro Chagas, STD/AIDS Clinical Research Lab, Av. Brasil 4365, Manguinhos, Rio de Janeiro 21040-900, Brazil

2 Hornet INC, Los Angeles, CA, USA

3 Brazilian Ministry of Health, Brasilia, DF, Brazil
To avoid the spread of COVID-19 and the collapse of the health system, the Brazilian Ministry of Health, Brazilian States Governors and City Mayors have adopted social distancing and community containment measures since March 2020. These measures have been criticized by part of the Federal government, albeit the continuous rise of new cases, no availability of effective treatment nor prevention and limited availability of hospital and intensive care units [3]. Despite the importance of such measures, low income Brazilians may face barriers to adhere to social distancing measures, especially due to financial constraints. Almost 14 million Brazilians live in low-income communities (favelas or "slums") [4] mostly concentrated in metropolitan areas of big cities, such as Rio de Janeiro and São Paulo. These communities are highly populated and have precarious living conditions, with limited access to hygiene and sanitation, posing sanitary recommendations as a challenge, thus increasing vulnerability to COVID-19 infection. Moreover, Brazil has a great proportion of informal jobs, especially among low-income individuals, with no possibility of doing home office, what may impact in adhering to social distancing. During the first quarter of 2020, unemployment rate was 
$12.2 \%$ corresponding to 12.9 million Brazilians unemployed [5], and it may increase between 50 and 100\% due to the COVID-19 pandemic impact [6], especially considering the limited social support measures adopted by the Brazilian government.

Adding to economic and social challenges, sexual minorities such as cisgender gay, bisexual and other men who have sex with men (MSM) and transgender/non binary (TGNB) individuals may be facing other vulnerabilities during the COVID-19 pandemic, such as lack of access to HIV prevention, treatment and care [7]. Brazil accounts for almost half of HIV cases in Latin America [8], with a disproportional prevalence of infection among some sexual minorities, such as MSM (18\%) and transgender women who have sex with men $(31 \%)$ [9-12]. Brazil has long been at the forefront of HIV treatment and prevention in Latin America [13]. The Brazilian Public Health System (SUS) provides free of charge antiretroviral therapy (ART) to HIV-infected individuals since 1996 and daily oral pre-exposure prophylaxis (PrEP) with emtricitabine and tenofovir disoproxil fumarate (FTC/TDF) to those at substantial HIV risk since December, 2017 [14]. In addition, sexual minorities, especially transgender women, often present housing instability that may impact in adherence to social distancing measures [15].

In this context, we conducted a web-based survey targeting Brazilian MSM and TGNB individuals to understand how social distancing measures and the COVID-19 pandemic are impacting their personal lives, sexual behavior, and PrEP/ART access and use. In addition, we assessed the factors associated with unattainability of maintaining social distancing.

\section{Methods}

\section{Study Design}

This cross-sectional web-based study, conducted during social distancing period (April 16 to May 31, 2020), recruited MSM and TGNB using a geosocial networking (GSN) app for sexual encounters (Hornet), WhatsApp groups and Facebook. Individuals who met eligibility criteria (age $\geq 18$ years, MSM and TGNB individuals, Brazilian resident) and acknowledged reading the informed consent were directed to the online questionnaire programmed on SurveyGizmo®. Cisgender men self-identifying heterosexual and cisgender women were excluded from this analysis. The Instituto Nacional de Infectologia Evandro Chagas (INI-Fiocruz) institutional review board (\#CAAE 82021918.0.0000.5262) reviewed and approved this study. No identification of participants was collected and no incentives were provided.

\section{Survey Instrument}

The survey instrument was composed of six sections (55 questions) addressing: sociodemographic information, social distancing/COVID-19 pandemic impact in personal life, substance use, HIV testing, PrEP and ART use/access and sexual behavior.

\section{Variables}

\section{Socio-demographic}

Variables were as following: age at the time of the survey (categorized in 3 brackets: 18 to $24 ; 25$ to 35 and $>35$ years); gender in cisgender men, transgender men, transgender women, and non-binary/gender fluid; sexual orientation in gay, bisexual, heterosexual or other (e.g. pansexual, asexual); race/color (categorized in white, black, pardo or mixed-black, native or indigenous and Asian); schooling (categorized in low $[\leq 12$ years or completed secondary school or less] and high [ $>12$ years or more than secondary school]). We also collected data on family monthly income, grouped into the following strata considering Brazilian minimum wage (MW) in 2020 ( $\mathrm{R} \$ 998$ or US\$268): low (up to $2 \mathrm{MW}$ ), middle (> 2-6 MW), and high (>6 MW). Region was defined according to the Brazilian administrative division: North (7 states), Northeast (9 states), Central-west (3 states and Federal District), South (3 states) and Southeast (4 states); individuals living in the metropolitan area of the State Capital were considered as resident of metro area.

\section{Social Distancing/COVID-19 Pandemic Impact In Personal Life}

Fear to be infected by COVID-19 had 5 categories: high, moderate, low, none or infected or previously infected by COVID-19. We asked how concerned individuals were if a close relative or friend got infected by COVID-19 (rate between 0 and 100); answers were stratified in 100, 99-75, 74-50, <50\%. Participants also answered how much social distancing measures impacted their personal life (high, medium, low/none) and which aspect was the most affected (economic, affective/sexual, family/friendship, or none). We also assessed challenges during social distancing/COVID-19 pandemic presented in a pre-determined list: access to hand sanitizer and water, salary/job reduced or lost, transportation availability, access to food, access to health/mental care support, access to daily medication/hormones and housing. Respondents could answer 
yes/no to any of the challenges. The question: "Were you unable to maintain recommended social distancing due to any reason, such as work or housing challenges?" (yes/no) assessed unattainability of maintaining social distancing.

\section{Mental Health, Binge Drinking and Substance Use}

Mental health problems were assessed by the question: "Have you felt depressed, lonely, angry, nightmares, panic attack, sleeping or concentration problems during the social distancing period?" (yes/no). Participants were also asked about suicidal thoughts and physical/sexual/emotional abuse (yes/no). Binge drinking [16] was evaluated with the question "During the social distancing period, did you drink 5 or more drinks in a couple of hours?" (yes/no). Tobacco and any illicit drug use during social distancing period were dichotomized into yes/no. Individuals answered about the habit of using alcohol, tobacco and illicit drug during that period (increased, decreased, or the same).

\section{HIV Testing}

HIV self-reported status derived from the question "Have you ever had an HIV test?", whose potential answers were positive, negative, or never.

\section{Pre-exposure Prophylaxis (PrEP)}

Participants self-reporting HIV negative/unknown status answered if they were using oral PrEP before the issuance of social distancing recommendations. Those on PrEP prior to social distancing answered if they stopped PrEP (no FTC/ TDF refill) after such recommendations and choose the main reason to stop from a selected list of options (including an open field for other reasons). Those who continued using PrEP answered about PrEP regimen (daily, event-driven PrEP, or [ED]-PrEP and other nonstandard regimens). We assessed awareness and intention to use PrEP for those not on PrEP prior to social distancing recommendations. Awareness was defined as a positive answer to the question "Have you ever heard of PrEP?". A brief explanation about PrEP was provided after this question. Intention to use PrEP was defined as the "High interest" answer to the question "Would you be using PrEP currently available at the Brazilian Public Health System (SUS) to prevent HIV?" with a five-point Likert scale as potential answers.

\section{Antiretroviral Therapy (ART)}

Participants self-reporting HIV-positive status answered about ART use (yes/no) and the impact of social distancing recommendations on ART refill. Those reporting "yes" also had to select the main reason to stop from pre-existing options (including an open field for other reasons). They rated ART adherence from 0 (missed all ART doses during social distancing period) to 100 (no missing dose). We dichotomized self-reported ART adherence in complete (rating $=100)$ and poor $($ rating $<100)$.

\section{Sexual Behavior, PrEP Eligibility Criteria and HIV Perceived Risk}

Participants self-reporting HIV-negative/unknown status answered questions on sexual behavior during social distancing period, including sex frequency, steady partner HIV status [HIV-negative, -unknown, -positive with undetectable viral load (VL), -positive with detectable/unknown VL, no steady partner], number of casual partners, condomless receptive anal sex with steady and casual partners, and transactional sex. Sex abstinence was defined as no physical contact with partners. Participants were also asked if the number of casual partners has changed during this period and the main venue used to find them.

PrEP eligibility criteria was based on Brazilian recommendations for PrEP use [17] and defined as one of the following during social distancing period: (1) condomless receptive anal sex, (2) sex with HIV-positive partner, and/or (3) transactional sex. The question "In your opinion, what is your risk of getting HIV during social distancing period?", which had five possible options ("No risk", "Low risk", "Moderate risk/50\%", "High risk", and Certain/100\%"), assessed the HIV perceived risk. We categorized that variable into three groups: "No risk", "Low risk", and "High risk" (which included the categories "Moderate risk/50\%", "High risk" and "Certain/100\%"), as previously described [18].

\section{Statistical Analysis}

Sociodemographic characteristics and HIV self-reported status were described considering the entire sample. We used chi-square test to compare sexual behavior, PrEP eligibility criteria and HIV perceived risk between PrEP users during social distancing period (on PrEP vs not on PrEP). We compared social distancing/COVID-19 pandemic impact in personal life, binge drinking and substance use according to gender (cisgender men vs. TGNB) using chi-square or Fisher's exact test when appropriate. Finally, we used logistic regression modeling to assess the factors associated with unattainability of maintaining social distancing. Variables were included in the adjusted model regardless of significant $\mathrm{p}$-value thresholds in univariate analysis. To build the model, race was dichotomized into white/Asian vs. non-white (black/mixed-black/native), and country region was dichotomized into Southeast/South vs. other, following previous study conducted among Brazilian MSM [18]. 
Analyses were performed using Software R version 4.0.0 [19].

\section{Results}

A total of 5490 individuals accessed the questionnaire, 715 (13.0\%) did not meet inclusion criteria or did not consent, and $3486(63.5 \%)$ completed it and were included in this analysis (Fig. 1). Median age was 32 years (interquartile range [IQR 27-40]); 505 (14.5\%) participants were aged 18-24 years; $61.3 \%(n=2137)$ were recruited on Hornet. The great majority of respondents were cisgender men (3400; 97.5\%), self-identified as gay $(2961 ; 84.9 \%)$ and lived in the Southeast Brazil $(2784 ; 80.4 \%)$. Non-white individuals accounted $44.0 \%(n=1534)$, about a third $(1252 ; 35.9 \%)$ had low schooling and $38.0 \%(n=1323)$, low family income (Table 1).

\section{Social Distancing/COVID-19 Pandemic}

About one quarter of participants reported unattainability of maintaining social distancing (917/3486; 26.3\%). Most of individuals had high/moderate fear to get infected by
COVID-19 (2699; 77.4\%), and $72.3 \%$ were very worried (scale: 75-100) about close relatives/friends getting infected (2519; 72.3\%) (Table 2). Only 61 (1.7\%) reported had being infected by COVID-19. Social distancing measures had highly impacted most of participants' lives $(2195 ; 63.0 \%)$, and the economic aspect was the most affected (1474; $42.3 \%$ ). Challenges more frequently reported during social distancing were: salary/job reduced or lost $(1575 ; 45.2 \%)$, access to hand sanitizer $(1201 ; 34.5 \%)$, and transportation availability $(676 ; 19.4 \%)$. Compared to MSM, TGNB individuals had more challenges to access food, hormones, health/mental care, medication refill, and higher frequency of unsafe housing $(\mathrm{p}<0.01)$.

\section{Mental Health and Substance Use}

TGNB individuals reported more mental health problems during the social distancing period, access to mental health care, and suicidal thoughts $(\mathrm{p}<0.001)$. Among respondents reporting alcohol use $(n=2181), 29.7 \%(n=647)$ reported an increased use during social distancing period. Almost half of the overall sample reported binge drinking (48.9\%, $\mathrm{n}=1705 / 3486$ ), (Table 3). Among tobacco smokers, 49.4\% (397/804) increased its use during this period. Any illicit

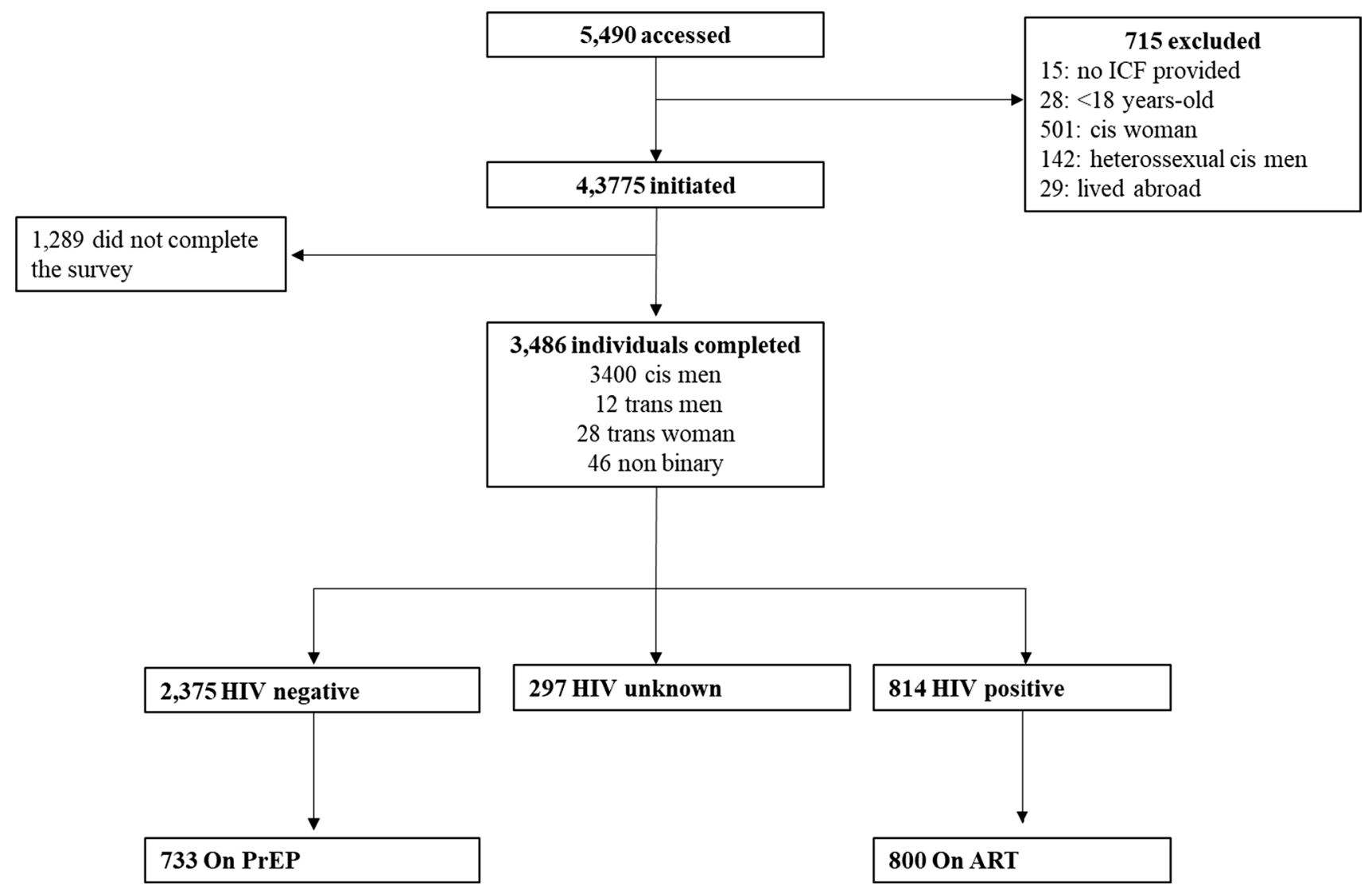

Fig. 1 Study flow-chart. Brazil, 2020 
Table 1 Characteristics of study population

\begin{tabular}{|c|c|}
\hline & $\mathrm{N}=3486(\%)$ \\
\hline \multicolumn{2}{|l|}{ Age (years) } \\
\hline Median & 32(IQR: 27-40) \\
\hline $18-24$ & $505(14.5)$ \\
\hline $25-35$ & $1627(46.7)$ \\
\hline$>35$ & $1354(38.8)$ \\
\hline \multicolumn{2}{|l|}{ Recruitment } \\
\hline Hornet & $2137(61.3)$ \\
\hline WhatsApp & $1098(31.5)$ \\
\hline Facebook & $251(7.2)$ \\
\hline \multicolumn{2}{|l|}{ Gender } \\
\hline Cisgender men & $3400(97.5)$ \\
\hline Transgender men & $12(0.3)$ \\
\hline Transgender women & $28(0.8)$ \\
\hline Non binary/gender fluid & $46(1.3)$ \\
\hline \multicolumn{2}{|l|}{ Sexual orientation } \\
\hline Gay & $2961(84.9)$ \\
\hline Bisexual & 438 (12.6) \\
\hline Heterosexual & $17(0.5)$ \\
\hline Other & $70(2.0)$ \\
\hline \multicolumn{2}{|l|}{ Race } \\
\hline White & $1927(55.3)$ \\
\hline Black & $494(14.2)$ \\
\hline Pardo/Mixed-black & $1005(28.8)$ \\
\hline Native & $35(1.0)$ \\
\hline Asian & $25(0.7)$ \\
\hline \multicolumn{2}{|l|}{ Schooling } \\
\hline Low & $1252(35.9)$ \\
\hline High & $2234(64.1)$ \\
\hline \multicolumn{2}{|l|}{ Family monthly income } \\
\hline Low & $1323(38.0)$ \\
\hline Middle & $1404(40.3)$ \\
\hline High & $759(21.8)$ \\
\hline \multicolumn{2}{|l|}{ Region } \\
\hline Southeast & $2784(80.4)$ \\
\hline South & $313(9.0)$ \\
\hline Central-west & $165(4.8)$ \\
\hline Northeast & $166(4.8)$ \\
\hline North & $33(1.0)$ \\
\hline \multicolumn{2}{|l|}{ Resident of metro area } \\
\hline Yes & $2636(76.2)$ \\
\hline No & $825(23.8)$ \\
\hline \multicolumn{2}{|l|}{ HIV self-reported status } \\
\hline Negative & $2375(68.1)$ \\
\hline Positive & $814(23.4)$ \\
\hline Unknown & $297(8.5)$ \\
\hline
\end{tabular}

Brazil, 2020

$\mathrm{N}=3486$ drug use was reported by $23.1 \%(n=806)$, and the most common were marijuana $(586 ; 16.8 \%)$ and cocaine $(233$; $6.7 \%) ; 30.4 \%$ reported increased use of illicit drugs during social distancing period. Comparing to MSM, TGNB people reported more tobacco and illicit drug use $(\mathrm{p}<0.001)$.

\section{HIV Status/PrEP and ART Access During Pandemic}

Most respondents reported to be HIV-negative (2375/3486; $68.1 \%)$ and $8.5 \%(n=297)$ reported unknown HIV status. Among HIV-negative respondents, $30.9 \%(n=733)$ were on oral PrEP before social distancing recommendations, mostly through the Public Health System (SUS) [PrEP SUS $(342 / 733 ; 46.7 \%)$ and the ImPrEP study $(338 / 733$; $46.1 \%)$ ]. A total of $68.5 \%$ (502/733) maintained daily oral PrEP during social distancing period, while 27.8\% (204/733) stopped it completely, $1.5 \%$ (11/733) used ED-PrEP, and $2.2 \%$ (16/733), nonstandard PrEP regimens. Main reasons for stopping PrEP use were: impediments to pick up PrEP refill at the health service $(95 / 204 ; 46.6 \%)$ and sexual abstinence $(81 / 204 ; 39.7 \%)$. Main reasons for continuing PrEP were: fear of HIV infection $(327 / 529 ; 61.8 \%)$, sex with casual partners $(90 / 529 ; 17.0 \%)$, HIV-positive partner $(63 / 529$; $11.9 \%$ ), and belief that PrEP protected against COVID-19 (49/529; 9.3\%).

The large majority of participants self-reporting HIVpositive status were on ART (800/814; 98.2\%), and $18.2 \%$ (146/800) reported poor ART adherence during social distancing period. Only $17.2 \%$ (138/800) reported impact of social distancing measures on ART refill; most frequent reasons were: fear of going out $(68 / 138 ; 49.2 \%)$, non-availability of public transportation $(29 / 138 ; 21.0 \%)$, and closing of health care unit $(21 / 138 ; 15.2 \%)$. Considering only those with poor adherence, $37.7 \%$ (55/146) reported impact on ART refill.

\section{Sexual Behavior}

Table 4 describes sexual behavior characteristics among HIV-negative/unknown status according to PrEP use during social distancing period. Overall, almost half of participants (1213/2672; 45.4\%) reported sex abstinence during social distancing period; among these, 28.8\% (349/1213) reported virtual sex. Most of participants reported decreased number of sexual partners during social distancing period. More than three quarters of respondents reported finding casual partners mainly online (779/1012; $76.8 \%$ ). Almost half of individuals who maintained any regimen of PrEP during social distancing period reported having sex $(273 / 529 ; 51.6 \%)$ and, compared to those not on PrEP, more condomless receptive anal sex, number of 
Table 2 Social distancing and COVID-19 pandemic impact in personal life according to gender

\begin{tabular}{|c|c|c|c|c|}
\hline & $\begin{array}{l}\text { Total } \\
\mathrm{N}=3486\end{array}$ & $\begin{array}{l}\text { Transgender / non } \\
\text { binary } \\
\mathrm{N}=86(2.5 \%)\end{array}$ & $\begin{array}{l}\text { Cisgender MSM } \\
\mathrm{N}=3400(97.5 \%)\end{array}$ & p-value \\
\hline Fear to get infected by COVID-19 & & & & 0.05 \\
\hline High & $1176(33.7)$ & $36(41.9)$ & $1140(33.5)$ & \\
\hline Moderate & $1523(43.7)$ & $30(34.9)$ & $1493(43.9)$ & \\
\hline Low & $495(14.2)$ & $17(19.8)$ & $478(14.1)$ & \\
\hline No & $231(6.6)$ & $1(1.2)$ & $230(6.8)$ & \\
\hline Infected or previously infected by COVID-19 & $61(1.7)$ & $2(2.3)$ & $59(1.7)$ & \\
\hline \multicolumn{5}{|c|}{ Concerned if close relatives/friends get infected by COVID-19 } \\
\hline 100 & $1435(41.2)$ & $40(46.5)$ & $1395(41.0)$ & 0.60 \\
\hline $99-75$ & $1084(31.1)$ & $27(31.4)$ & $1057(31.1)$ & \\
\hline $74-50$ & $669(19.2)$ & $12(14.0)$ & $657(19.3)$ & \\
\hline$<50$ & $298(8.5)$ & $7(8.1)$ & $291(8.6)$ & \\
\hline Impact of social distancing measures in personal life & & & & 0.37 \\
\hline High & $2195(63.0)$ & $59(68.6)$ & $2136(62.8)$ & \\
\hline Medium & $894(25.6)$ & $21(24.4)$ & $873(25.7)$ & \\
\hline Low/no & $397(11.4)$ & $6(7.0)$ & $391(11.5)$ & \\
\hline Aspect most impacted & & & & 0.11 \\
\hline Economic & $1474(42.3)$ & $47(54.7)$ & $1427(42.0)$ & \\
\hline Affective/sexual & $988(28.3)$ & $17(19.8)$ & $971(28.6)$ & \\
\hline Family/friendship & $914(26.2)$ & $20(23.3)$ & $894(26.3)$ & \\
\hline None & $110(3.2)$ & $2(2.3)$ & $108(3.2)$ & \\
\hline \multicolumn{5}{|l|}{ Challenges } \\
\hline Salary/job reduced or lost & $1575(45.2)$ & $44(51.2)$ & $1531(45.0)$ & 0.26 \\
\hline Access to hand sanitizer & $1201(34.5)$ & $35(40.7)$ & $1166(34.3)$ & 0.22 \\
\hline Transportation availability & $676(19.4)$ & $23(26.7)$ & $653(19.2)$ & 0.08 \\
\hline Access to food & $451(12.9)$ & $19(22.1)$ & $432(12.7)$ & 0.01 \\
\hline Access to health care & $396(11.4)$ & $23(26.7)$ & $373(11.0)$ & $<0.001$ \\
\hline Access to mental health care & $319(9.2)$ & $26(30.2)$ & $293(8.6)$ & $<0.001$ \\
\hline Access to daily medication & $215(6.2)$ & $15(17.4)$ & $200(5.9)$ & $<0.001$ \\
\hline Access to hormones & $54(1.5)$ & $15(17.4)$ & $39(1.1)$ & $<0.001$ \\
\hline Access to water & $43(1.2)$ & $3(3.5)$ & $40(1.2)$ & 0.06 \\
\hline Unable to find housing & $22(0.6)$ & $0(0)$ & $22(0.6)$ & 0.45 \\
\hline Unsafe Housing & $21(0.6)$ & $4(4.7)$ & $17(0.5)$ & $<0.001$ \\
\hline
\end{tabular}

Brazil, 2020

$\mathrm{N}=3486$

casual partners and transactional sex $(\mathrm{p}<0.001)$. Almost a quarter of those not on PrEP $(23.9 \%$; 513/2143) were eligible for PrEP and 10.5\% $(n=225)$ reported condomless receptive anal sex with casual partner, but only $8.5 \%$ (183/2143) reported high HIV perceived risk. Among those who stopped PrEP during the social distancing period, 33.3\% (68/204) maintained PrEP eligibility and could have continued its use. Considering those not on PrEP prior to this period, $86.6 \%$ were aware of PrEP (1679/1939), and 22.9\% (445/1939) had PrEP eligibility, among whom $48.1 \%$ (214/445) reported intention to use PrEP.

\section{Factors Associated with Unattainability of Maintaining Social Distancing}

Black/Pardo/native race (adjusted odds ratio [aOR] 1.23; 95\% confidence interval [CI] 1.05-1.44), lower schooling (aOR 1.47; 95\% CI 1.23-1.75), lower income (aOR 1.30; 95\% CI 1.03-1.66), and binge drinking (aOR 1.28; 95\% CI 1.09-1.49) were associated with unattainability of maintaining social distancing in the logistic multivariate analysis (Table 5). There was no difference in the unattainability of maintaining social distancing according to self-reported HIV status nor gender/sexual orientation. 
Table 3 Mental health, binge drinking and substance use during social distancing according to gender

\begin{tabular}{|c|c|c|c|c|}
\hline & $\begin{array}{l}\text { Total } \\
\mathrm{N}=3486\end{array}$ & $\begin{array}{l}\text { Transgender/ } \\
\text { non binary } \\
\mathrm{N}=86(2.5 \%)\end{array}$ & $\begin{array}{l}\text { Cisgender MSM } \\
\mathrm{N}=3400(97.5 \%)\end{array}$ & $\mathrm{p}$-value \\
\hline Mental health problems & $2290(65.7)$ & $76(88.4)$ & $2214(65.1)$ & $<0.001$ \\
\hline Suicidal thoughts & $400(11.5)$ & $23(26.7)$ & $377(11.1)$ & $<0.001$ \\
\hline Physical, sexual or emotional abuse & $78(2.2)$ & $2(2.3)$ & $76(2.2)$ & 0.96 \\
\hline Alcohol use (yes) & $2181(62.6)$ & $52(60.5)$ & $2129(62.6)$ & 0.68 \\
\hline Frequency of Alcohol use & & & & 0.34 \\
\hline Increased & 647 (29.7) & $13(25.0)$ & $634(29.8)$ & \\
\hline Same & $893(40.9)$ & $19(36.5)$ & $874(41.1)$ & \\
\hline Decreased & $641(29.4)$ & $20(38.5)$ & $621(29.2)$ & \\
\hline Binge drinking & $1705(48.9)$ & $43(50.0)$ & $1662(48.9)$ & 0.84 \\
\hline Tobacco smoking & $804(23.1)$ & $32(37.2)$ & $772(22.7)$ & 0.002 \\
\hline Tobacco smoking frequency & & & & 0.10 \\
\hline Increased & $397(49.4)$ & $13(40.6)$ & $384(49.7)$ & \\
\hline Same & $198(24.6)$ & $6(18.8)$ & $192(24.9)$ & \\
\hline Decreased & $163(20.3)$ & $12(37.5)$ & $151(19.6)$ & \\
\hline Started & $46(5.7)$ & $1(3.1)$ & $45(5.8)$ & \\
\hline Any illicit drug use & $806(23.1)$ & $33(38.4)$ & $773(22.7)$ & $<0.001$ \\
\hline Illicit drug use frequency & & & & 0.991 \\
\hline Increased & $245(30.4)$ & $10(30.3)$ & $235(30.4)$ & \\
\hline Same & $223(27.7)$ & $10(30.3)$ & $213(27.6)$ & \\
\hline Initiated other illicit drugs & $20(2.5)$ & $1(3.0)$ & $19(2.5)$ & \\
\hline Decreased & $274(34.0)$ & $10(30.3)$ & $264(34.2)$ & \\
\hline Started using illicit drugs & $44(5.5)$ & $2(6.1)$ & $42(5.4)$ & \\
\hline
\end{tabular}

Brazil, 2020

$\mathrm{N}=3486$

\section{Discussion}

In this study, we have shown that maintaining social distancing is a challenge among MSM and TGNB surveyed. Socioeconomic (low schooling and low income) and racial disparities were associated with unattainability in maintaining social distancing among these groups. Social distancing measures had highly impacted most of participants' lives, and TGNB populations reported more mental health problems and more challenges to access health care than cisgender MSM.

Non-white, low schooling, and low income MSM and TGNB had higher odds of unattainability in maintaining social distancing. Our findings reinforce that social and racial inequalities are also of utmost importance among sexual minorities. Brazil is a highly stigmatized, transphobic, and homophobic country [20,21], and the adverse context surrounding sexual minorities populations in the country may act synergistically with the social disruption linked to the pandemic and disproportionally affect MSM and TGNB. Moreover, despite being the 9th largest economy by nominal Gross Domestic Product (GDP $=$ US\$ 1.9 trillion), Brazil is the 9th most unequal country in the world and the 1st in the Americas according to GINI index from The World Bank [22, 23]. Inequality is a major challenge regardless of the population group, and racial disparities, which have been historical since the inception of the country, have now reached one of their worst periods according to some authors [24, 25]. This unfair system forces low income people, mostly of black and Pardo race and of lower schooling, to maintain their professional activities, which are frequently informal or unstable, even during social distancing recommendations. For those people, home office and social distancing are not an option [26]. Besides that, Brazilian social policies have been dismantled, and the governmental support during the epidemic is very limited. Recent data has shown that $37 \%$ of favela inhabitants who requested the Federal COVID-19 emergency support (US\$120 for 3 months) have not received it, although $73 \%$ of these families have lost half or the entire family income [27]. The COVID19 pandemic emphasizes the relationship between social/ racial disparities and health outcomes [28], as seen in recent studies conducted in Brazil, which identified that adults with lower schooling presented higher prevalence of risk factors for severe COVID-19 compared to university 
Table 4 Sexual behavior, PrEP eligibility criteria and HIV perceived risk among individuals reporting negative/unknown HIV status according to PrEP use during social distancing period

\begin{tabular}{|c|c|c|c|c|}
\hline & $\begin{array}{l}\text { Total } \\
\mathrm{N}=2672\end{array}$ & $\begin{array}{l}\text { Not on PrEP } \\
N=2143(80.2 \%)\end{array}$ & $\begin{array}{l}\text { On PrEP } \\
\mathrm{N}=529(19.8 \%)\end{array}$ & $\mathrm{p}$-value \\
\hline \multicolumn{5}{|l|}{ Sex during social distancing period } \\
\hline Yes, with any partner & $1012(37.9)$ & $739(34.5)$ & $273(51.6)$ & $<0.001$ \\
\hline Yes, only with steady partners & $447(16.7)$ & $326(15.2)$ & $121(22.9)$ & \\
\hline Sex abstinence & $1213(45.4)$ & $1078(50.3)$ & $135(25.5)$ & \\
\hline Steady partners & & & & $<0.001$ \\
\hline No & $1736(65.0)$ & $1458(68.0)$ & $278(52.6)$ & \\
\hline Yes, HIV negative & $647(24.2)$ & $495(23.1)$ & $152(28.7)$ & \\
\hline Yes, HIV positive undetectable VL & $150(5.6)$ & $82(3.8)$ & $68(12.9)$ & \\
\hline Yes, HIV positive detectable/unknown VL & $14(0.5)$ & $8(0.4)$ & $6(1.1)$ & \\
\hline Yes, HIV unknown & $125(4.7)$ & $100(4.7)$ & $25(4.7)$ & \\
\hline Condomless receptive anal sex with steady partners & & & & $<0.001$ \\
\hline No & $2244(84.0)$ & $1874(87.4)$ & $370(69.9)$ & \\
\hline Yes & $428(16.0)$ & $269(12.6)$ & $159(30.1)$ & \\
\hline Number of casual partners & & & & $<0.001$ \\
\hline No & $1673(62.6)$ & $1415(66.0)$ & $258(48.8)$ & \\
\hline 1 & $381(14.3)$ & $302(14.1)$ & $79(14.9)$ & \\
\hline 2 to 5 & $505(18.9)$ & $357(16.7)$ & $148(28.0)$ & \\
\hline$>5$ & $113(4.2)$ & $69(3.2)$ & $44(8.3)$ & \\
\hline Condomless receptive anal sex with casual partner & & & & $<0.001$ \\
\hline No & $2292(85.8)$ & $1918(89.5)$ & $374(70.7)$ & \\
\hline Yes & $380(14.2)$ & $225(10.5)$ & $155(29.3)$ & \\
\hline Change in number of sexual partners & & & & 0.086 \\
\hline Increased & $91(3.4)$ & $75(3.5)$ & $16(3.0)$ & \\
\hline Same & $837(31.3)$ & $691(32.2)$ & $146(27.6)$ & \\
\hline Decreased & $1744(65.3)$ & $1377(64.3)$ & $367(69.4)$ & \\
\hline Transactional sex & & & & 0.003 \\
\hline No & $2594(97.1)$ & 2092 (97.6) & $502(94.9)$ & \\
\hline Yes & $78(2.9)$ & $51(2.4)$ & $27(5.1)$ & \\
\hline Main venue to find casual partners $(n=1012)$ & & & & 0.357 \\
\hline Online & 779 (76.8) & $574(77.6)$ & $205(74.8)$ & \\
\hline Other & $235(23.2)$ & $166(22.4)$ & $69(25.2)$ & \\
\hline PrEP eligibility criteria & & & & $<0.001$ \\
\hline No & $1857(69.5)$ & $1630(76.1)$ & $227(42.9)$ & \\
\hline Yes & $815(30.5)$ & $513(23.9)$ & $302(57.1)$ & \\
\hline HIV perceived risk & & & & $<0.001$ \\
\hline No risk & $1581(59.2)$ & $1306(60.9)$ & $275(52.0)$ & \\
\hline Low risk & $870(32.6)$ & $654(30.5)$ & $216(40.8)$ & \\
\hline High & $221(8.3)$ & $183(8.5)$ & 38 (7.2) & \\
\hline
\end{tabular}

Brazil, 2020

$\mathrm{N}=2,672$

graduated [29] and that black and Pardo populations had higher risk of mortality compared to white Brazilians [30].

Social distancing measures had highly impacted sexual minorities, and gender disparities were observed. Challenges related to access to hand sanitizer and economic issues have been equally reported regardless of gender. However, TGNB reports of challenges in accessing health care are worrisome. Transgenders usually face relevant barriers in accessing health care that may be magnified when compared to other groups [31]. In a qualitative study among Brazilian transgender women, past experiences of transgender-identity related discrimination was the most prominent barrier to seek for 
Table 5 Factors associated with unattainability of maintaining social distancing

\begin{tabular}{|c|c|c|c|}
\hline & \multicolumn{2}{|c|}{ Unattainability of maintaining social distancing } & \multirow[t]{2}{*}{$\mathrm{aOR}(95 \% \mathrm{CI})$} \\
\hline & Yes $(n=917)$ & No $(n=2,569)$ & \\
\hline Age (years) & 32 (IQR: 26-38) & 33 (IQR:27-41) & $0.99(0.98-1.00)$ \\
\hline \multicolumn{4}{|l|}{ Gender } \\
\hline Cisgender men & $891(97.2)$ & 2509 (97.7) & $1.01(0.63-1.67)$ \\
\hline Transgender/non binary & $26(2.8)$ & $60(2.3)$ & Ref \\
\hline \multicolumn{4}{|l|}{ Sexual orientation } \\
\hline Gay & $755(82.3)$ & $2206(85.9)$ & $0.83(0.68-1.03)$ \\
\hline Other & $162(17.7)$ & $363(14.1)$ & Ref \\
\hline \multicolumn{4}{|l|}{ Race } \\
\hline White/Asian & $453(49.4)$ & $1499(58.3)$ & Ref \\
\hline Black/Pardo/Native & $464(50.6)$ & $1070(41.7)$ & $1.23(1.05-1.44)$ \\
\hline \multicolumn{4}{|l|}{ Schooling } \\
\hline Low & $414(45.1)$ & $838(32.6)$ & $1.47(1.23-1.75)$ \\
\hline High & $503(54.9)$ & $1731(67.4)$ & Ref \\
\hline \multicolumn{4}{|l|}{ Income } \\
\hline Low & $399(43.5)$ & $924(36.0)$ & $1.30(1.03-1.66)$ \\
\hline Middle & $372(40.6)$ & $1032(40.2)$ & $1.34(1.08-1.68)$ \\
\hline High & $146(15.9)$ & $613(23.9)$ & Ref \\
\hline \multicolumn{4}{|l|}{ Region } \\
\hline Southeast/South & $798(87.6)$ & $2299(90.2)$ & $0.79(0.62-1.01)$ \\
\hline Other & 113 (12.4) & $251(9.8)$ & Ref \\
\hline \multicolumn{4}{|l|}{ Self-reported HIV status } \\
\hline Positive & 208 (22.7) & $606(23.6)$ & Ref \\
\hline Negative & $618(67.4)$ & 1757 (68.4) & $1.03(0.85-1.24)$ \\
\hline Unknown & $91(9.9)$ & $206(8.0)$ & $1.04(0.76-1.41)$ \\
\hline \multicolumn{4}{|l|}{ Binge drinking } \\
\hline No & $422(46.0)$ & 1359 (52.9) & Ref \\
\hline Yes & $495(54.0)$ & $1210(47.1)$ & $1.28(1.09-1.49)$ \\
\hline \multicolumn{4}{|l|}{ Illicit drug use } \\
\hline No & 721 (78.6) & 1959 (76.3) & Ref \\
\hline Yes & $196(21.4)$ & $610(23.7)$ & $0.85(0.70-1.02)$ \\
\hline
\end{tabular}

Brazil, 2020. $\mathrm{N}=3,486$

Bold values indicate $\mathrm{p}<0.01$

$a O R$ adjusted $\mathrm{OR}, I Q R$ interquartile range
PrEP or health care in general [32]. Of note, Brazil is the country with the highest rate of murders against transgenders, 118.5 cases per year since 2008 [20]. Our findings on mental health problems, suicidal thoughts and tobacco/illicit drug use, although restricted to this online sample, indicate that social distancing measures may be disproportionally affecting TGNB individuals. Transphobia and stigma may lead to the high rates of mental health problems and substance use among transgender women in Brazil [9, 33], and the COVID-19 pandemic may be an additional burden for this population. In-depth assessments among transgender populations are necessary to better understand such associations. Moreover, online mental health support specific for these populations could be implemented by the Public Health System.
Another concern related to the COVID-19 pandemic relates to HIV vulnerability, access to HIV care and prevention. Although HIV high-risk behavior was more frequent among participants on PrEP compared to those not on PrEP during the social distancing period, almost a quarter of individuals not on PrEP were at substantial HIV risk. Most of respondents continued their medications (PrEP or ART), but an important percentage of people reported barriers to pick up medication refill. Among those reporting impediments to pick up PrEP refill at the health service, $40 \%$ (38/95) maintained PrEP eligibility criteria and could have continued its use. We identified a high percentage of poor ART adherence (20\%), considering the short period since social recommendations initiation, which is consistent with ART adherence data before COVID-19 pandemic [34]. People living with 
HIV in China also reported difficulties to access ART during the COVID-19 pandemic [7]. In Central and Eastern Europe, there have been concerns regarding a shortage of resources and an inevitable impact on HIV care. To avoid PrEP/ART shortage, the Brazilian Ministry of Health has recommended an extension of the PrEP refill dispensation from 90- to 120days and for ART from 90- to 180-days [35]. In addition, telemedicine and HIV self-testing have been used as options to maintain PrEP programs, including in Brazil [36-38]. These and other initiatives such as PrEP/ART home delivery would be essential to avoid medication shortage. Future impacts of COVID-19 pandemic on HIV epidemics are yet to be established.

Our results show that more than half of MSM and TGNB reported sexual activity during social distancing period, although the majority decreased the number of sexual partners. In a large web-based survey conducted among 11,367 MSM in Brazil before COVID pandemic, only $8 \%$ reported no sex in previous 6 months [39]. Although the recall time frames used in the surveys are different, this indicates a strong change in sexual behavior among this population. This is corroborated by the fact that $30 \%$ had PrEP eligibility criteria in the present survey, while $70 \%$ had the same criteria in the previous survey [39]. Almost half of PrEP users engaged in higher risk behaviors, indicating that health services in Brazil should continue PrEP provision for those populations. However, some PrEP users were not at substantial HIV risk and could have stopped PrEP. In such cases, ED-PrEP currently recommended by WHO [40] could be an option [17]. Awareness of PrEP among non-PrEP users was higher than previously reported [39, 41-43], showing that efforts of non-governmental, civil society, and projects such as ImPrEP [44] to advertise PrEP information on social media and dating apps have been effective. Conversely, only half of respondents not on PrEP showed interest in using PrEP. This could be explained by the misinformation on PrEP efficacy or side effects [43] and by the fact that daily oral pills may be a regimen not suitable for all individuals. These individuals could be benefited by other prevention technologies on the pipeline, such as long-acting injectable PrEP [45], and by continuous education programs on PrEP.

This study has limitations. First, web-based studies are not probabilistic sampling strategies, precluding the generalization of the findings to all Brazilian MSM and TGNB populations. Moreover, our findings are based on those who have access to cellphones and who use GSN apps or social media, thus they are not generalizable to all MSM and TGNB in Brazil. Nevertheless, recent data show that $85 \%$ of Brazilians have mobile phones [46] and $79 \%$ have access to internet connection [47]. Also, the cross-sectional study design precludes to infer causality and the direction of association. In addition, we do not have pre-COVID-19 period data for some of the measures. Subsequent surveys are planned to understand sexual behavior and PrEP use during relaxing of social distancing measures and posCOVID-19 pandemic period in Brazil. Other limitation is that all collected data were self-reported by participants and may be subject to bias. However, individuals tend to be more open and honest through web-based surveys, thereby reducing social desirability bias [48]. Lastly, other issues specific to LGBTQI + populations (e.g. discrimination, stigma or homonegativity) were not explored in this study.

\section{Conclusion}

Maintaining social distancing is challenging, particularly for the most vulnerable MSM and TGNB people, likely increasing their risk of acquiring COVID-19. Furthermore, these individuals may also suffer the biggest consequences of the COVID-19 pandemic on the health care system, thus impacting their HIV care and prevention and ultimately the Brazilian HIV epidemic control. Tailored social, economic and mental health support policies during the COVID-19 pandemic should be made available to those individuals. In the context of the COVID-19 pandemic, challenges for PrEP and ART access will demand the implementation of innovative solutions to fulfill the needs of prevention and treatment and avoid the expansion of the HIV epidemic in Brazil.

Acknowledgements This project was made possible, thanks to Unitaid's funding and support. Unitaid accelerates access to innovative health products and lays the foundations for their scale-up by countries and partners. Unitaid is a hosted partnership of the WHO. TST acknowledges funding from the National Council of Technological (CNPq, \#28/2018). BG acknowledges funding from the National Council of Technological and Scientific Development and the Research Funding Agency of the State of Rio de Janeiro (Programa Cientista do Nosso Estado; Edital No. 03/2018). This work has been presentated as late breaker in a Poster Session at the 23rd International AIDS Conference (AIDS 2020: Virtual), held on 6-10 July 2020.

\section{References}

1. WHO. WHO Timeline - COVID-19. https://www.who.int/newsroom/detail/27-04-2020-who-timeline-covid-19. Accessed 4 Jun 2020.

2. Brasil. Painel Coronavírus. 2020. https://covid.saude.gov.br/. Accessed 30 July 2020.

3. The Lancet. COVID-19 in Brazil: "So what?". Lancet. 2020;395(10235): 1461.

4. Agência Brasil. Brasil tem 13,6 milhões de pessoas morando em comunidades. https://agenciabrasil.ebc.com.br/geral/noticia/202001/moradores-de-favelas-movimentam-r-1198-bilhoes-por-ano. Accessed 3 Jun 2020.

5. IBGE. Pesquisa Nacional por Amostra de Domicílios Contínua - PNAD Contínua. 2020. https://www.ibge.gov.br/estatisticas/ sociais/trabalho/9173-pesquisa-nacional-por-amostra-de-domic ilios-continua-trimestral.html $?=\& \mathrm{t}=$ resultados. 
6. Anadolu Agency. COVID-19 triggers massive unemployment in Latin America. 2020. https://www.aa.com.tr/en/americas/covid -19-triggers-massive-unemployment-in-latin-america/1825029.

7. Jiang $\mathrm{H}$, Zhou $\mathrm{Y}$, Tang W. Maintaining HIV care during the COVID-19 pandemic. Lancet HIV. 2020;7:e308.

8. UNAIDS. UNAIDS data 2019 [Internet]. 2019. https://www.unaid s.org/sites/default/files/media_asset/2019-UNAIDS-data_en.pdf. Accessed 24 Apr 2020.

9. Grinsztejn B, Jalil EM, Monteiro L, Velasque L, Moreira RI, Garcia ACF, et al. Unveiling of HIV dynamics among transgender women: a respondent-driven sampling study in Rio de Janeiro, Brazil. Lancet HIV. 2017;4(4):e169-e176176.

10. Kerr L, Kendall C, Guimarães MDC, Salani Mota R, Veras MA, Dourado I, et al. HIV prevalence among men who have sex with men in Brazil: results of the 2nd national survey using respondentdriven sampling. Medicine. 2018;97:S9-15.

11. De Boni R, Veloso VG, Grinsztejn B. Epidemiology of HIV in Latin America and the Caribbean. Curr Opin HIV AIDS. 2014;9(2):192-8.

12. Luz PM, Veloso VG, Grinsztejn B. The HIV epidemic in Latin America: accomplishments and challenges on treatment and prevention. Curr Opin HIV AIDS. 2019;14(5):366-73.

13. Galea JT, Baruch R, Brown B. ¡PrEP Ya! Latin America wants PrEP, and Brazil leads the way. Lancet HIV. 2018;5(3):e110-e11212.

14. WHO. Brazil begins PrEP roll-out on World AIDS Day [Internet]. World Health Organization. 2017. Available from: https://www. who.int/hiv/mediacentre/news/brazil-prep/en/. Accessed 29 Oct 2018.

15. Jalil EM, Wilson EC, Luz PM, Velasque L, Moreira RI, Castro $\mathrm{CV}$, et al. HIV testing and the care continuum among transgender women: population estimates from Rio de Janeiro, Brazil. J Int AIDS Soc. 2017;20(1):21873.

16. National Institute on Alcohol Abuse and Alcoholism (NIAAA), Abuse and Alcoholism (NIAAA). NIAAA approves definition of binge drinking [Internet]. 2004. https://pubs.niaaa.nih.gov/publi cations/Newsletter/winter2004/Newsletter_Number3.pdf

17. Brasil, Ministério da Saúde. Protocolo Clínico e Diretrizes Terapêuticas para Profilaxia Pré-Exposição (PrEP) de Risco à Infecção pelo HIV [Internet]. 2018. https://www.aids.gov.br/ pt-br/pub/2017/protocolo-clinico-e-diretrizes-terapeuticas-paraprofilaxia-pre-exposicao-prep-de-risco

18. Torres TS, Marins LMS, Veloso VG, Grinsztejn B, Luz PM. How heterogeneous are MSM from Brazilian cities? An analysis of sexual behavior and perceived risk and a description of trends in awareness and willingness to use pre-exposure prophylaxis. BMC Infect Dis. 2019;19(1):1067.

19. The R Project for Statistical Computing. [cited 2020 May 26]. Available from: https://www.r-project.org/

20. Benevides BG, Nogueira SNB. Dossiê assassinatos contra travestis brasileiras e violência e transexuais em 2019 [Internet]. 2020. https://antrabrasil.files.wordpress.com/2020/01/dossic3aa-dosassassinatos-e-da-violc3aancia-contra-pessoas-trans-em-2019. pdf. Accessed 11 Jun 2020.

21. Grupo Gay Bahia. RELATÓRIOS ANUAIS DE MORTES LGBTI+ [Internet]. https://grupogaydabahia.com.br/relatorios -anuais-de-morte-de-lgbti/. Accessed 4 May 2020.

22. The world bank. GINI index (World Bank estimate) [Internet]. https://data.worldbank.org/indicator/SI.POV.GINI?most_recen t_value_desc $=$ true

23. UNITED NATIONS ECONOMIC COMMISSION FOR LATIN AMERICA AND THE CARIBBEAN. SOCIAL PANORAMA OF LATIN AMERICA 2019. [Internet]. 2020. https://www.cepal .org/en/publications/44989-social-panorama-latin-america-2019. Accessed 4 Jun 2020
24. Brasil de Fato. "We're living one of the worst moments of Brazilian racism," writer says [Internet]. https://www.brasildefato.com. br/2019/05/13/were-living-one-of-the-worst-moments-of-brazi lian-racism-writer-says. Accessed 17 Jul 2020.

25. United Nations. Racial Discrimination and Miscegenation: The Experience in Brazil [Internet]. Racial Discrimination and Miscegenation: The Experience in Brazil. https://www.un.org/en/chron icle/article/racial-discrimination-and-miscegenation-experience -brazil. Accessed 17 Jul 2020.

26. DW Brasil. Epidemia de coronavírus expõe vulnerabilidades da "uberização" [Internet]. https://www.dw.com/pt-br/epidemia-decoronav\%C3\%ADrus-exp\%C3\%B5e-vulnerabilidades-da-uberi za\%C3\%A7\%C3\%A3o/a-52830974. Accessed 11 Jun 2020.

27. UOL. 3,9 milhões das famílias mais ricas recebem auxílio de R\$ 600, diz pesquisa. [Internet]. https://economia.uol.com.br/notic ias/redacao/2020/06/03/pesquisa-instituto-locomotiva-auxilioemergencial.htm. Accessed 4 Jun 2020.

28. Bilal U, Alazraqui M, Caiaffa WT, Lopez-Olmedo N, Martinez-Folgar K, Miranda JJ, et al. Inequalities in life expectancy in six large Latin American cities from the SALURBAL study: an ecological analysis. Lancet Planetary Health. 2019;3(12):e503-e510510.

29. Rezende LFM, Thome B, Schveitzer MC, de Souza-Júnior PRB, Szwarcwald CL. Adults at high-risk of severe coronavirus disease-2019 (Covid-19) in Brazil. Rev Saude Publica. 2020;54:50.

30. Baqui P, Bica I, Marra V, Ercole A, van der Schaar M. Ethnic and regional variations in hospital mortality from COVID-19 in Brazil: a cross-sectional observational study. Lancet Glob Health. 2020;8:e1018.

31. Safer JD, Coleman E, Feldman J, Garofalo R, Hembree W, Radix A, et al. Barriers to healthcare for transgender individuals. Curr Opin Endocrinol Diab Obes. 2016;23(2):168-71.

32. Wilson EC, Jalil EM, Castro C, Martinez Fernandez N, Kamel L, Grinsztejn B. Barriers and facilitators to PrEP for transwomen in Brazil. Glob Public Health. 2019;14(2):300-8.

33. Garcia Ferreira AC, Esteves Coelho L, Jalil EM, Luz PM, Friedman RK, Guimarães MRC, et al. Transcendendo: a cohort study of HIV-infected and uninfected transgender women in Rio de Janeiro, Brazil. Transgender Health. 2019;4(1):107-17.

34. de Costa M, Torres TS, Coelho LE, Luz PM. Adherence to antiretroviral therapy for HIV/AIDS in Latin America and the Caribbean: Systematic review and meta-analysis. J Intern AIDS Soc. 2018;21(1):e25066.

35. Ministério da Saúde. OFÍCIO CIRCULAR No 8/2020/CGAHV/. DCCI/SVS/MS [Internet]. 2020. https://www.aids.gov.br/pt-br/ legislacao/oficio-circular-no-82020cgahvdccisvsms

36. Barney A, Buckelew S, Mesheriakova V, Raymond-Flesch M. The COVID-19 pandemic and rapid implementation of adolescent and young adult telemedicine: challenges and opportunities for innovation. J Adolesc Health. 2020. https://doi.org/10.1016/j. jadohealth.2020.05.006.

37. Hoagland B, Torres TS, Bezerra DRB, Geraldo K, Pimenta C, Veloso VG, et al. Telemedicine as a tool for PrEP delivery during the COVID-19 pandemic in a large HIV prevention service in Rio de Janeiro-Brazil. Braz J Infect Dis. 2020. https://doi. org/10.1016/j.bjid.2020.05.004.

38. Dourado I, Magno L, Soares F, Massa P, Nunn A, et al. Adapting to the COVID-19 pandemic: continuing HIV prevention services for adolescents through telemonitoring, Brazil. AIDS Behav. 2020;24:1994.

39. Torres TS, Luz PM, De Boni RB, de Vasconcellos MTL, Hoagland B, Garner A, et al. Factors associated with PrEP awareness according to age and willingness to use HIV prevention technologies: the 2017 online survey among MSM in Brazil. AIDS Care. 2019;31(10):1193-202. 
40. WHO. What's the $2+1+1$ ? Event-driven oral pre-exposure prophylaxis to prevent HIV for men who have sex with men: Update to WHO's recommendation on oral PrEP. https://www.who.int/hiv/ pub/prep/211/en/. Accessed 4 Jun 2020 Jun 4.

41. Torres TS, De Boni RB, de Vasconcellos MT, Luz PM, Hoagland B, Moreira RI, et al. Awareness of prevention strategies and willingness to use preexposure prophylaxis in Brazilian men who have sex with men using apps for sexual encounters: online cross-sectional study. JMIR Public Health Surveill. 2018;4(1):e11.

42. Hoagland B, De Boni RB, Moreira RI, Madruga JV, Kallas EG, et al. Awareness and willingness to use pre-exposure prophylaxis (PrEP) among men who have sex with men and transgender women in Brazil. AIDS Behav. 2017;21(5):1278-87.

43. Torres TS, Konda KA, Vega-Ramirez EH, Elorreaga OA, DiazSosa D, Hoagland B, et al. Factors associated with willingness to use pre-exposure prophylaxis in Brazil, Mexico, and Peru: webbased survey among men who have sex with men. JMIR Public Health Surveill. 2019;5(2):e13771.

44. ImPrEP study team. ImPrEP Facebook fanpage [Internet]. 2020. https://www.facebook.com/imprepbrasil/
45. Coelho LE, Torres TS, Veloso VG, Landovitz RJ, Grinsztejn B. Pre-exposure prophylaxis 20: new drugs and technologies in the pipeline. Lancet HIV. 2019;6(11):e788-e799799.

46. Comitê Gestor da Internet no Brasil (CGIBR). J2 - INDIVÍDUOS QUE POSSUEM TELEFONE CELULAR 2019 [Internet]. 2020. https://cetic.br/pt/tics/domicilios/2019/individuos/J2/

47. Comitê Gestor da Internet no Brasil (CGIBR). C2A - USUÁRIOS DE INTERNET - INDICADOR AMPLIADO 2019 [Internet]. 2019. https://cetic.br/pt/tics/domicilios/2019/individuos/C2A/. Accessed 4 Jun 2020.

48. Heerwegh D. Mode differences between face-to-face and web surveys: an experimental investigation of data quality and social desirability effects. Int J Public Opin Res. 2009;21(1):111-21.

Publisher's Note Springer Nature remains neutral with regard to jurisdictional claims in published maps and institutional affiliations. 